ISSN 1817-3721, E-ISSN 1818-8745

Plant Tissue Cult. \& Biotech. 28(2): 261-268, 2018 (December)

CBangladesh Assoc. for Plant Tissue Culture \& Biotechnology

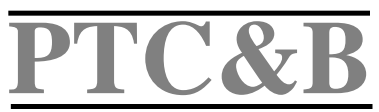

\title{
Evaluation of the Genotype-dependency of the Leaf- based Regeneration and Transformation System in Maize
}

\section{Saeideh Ebrahimzadeh and Mohammad Ahmadabadi*}

Department of Biotechnology, Faculty of Agriculture, Azarbaijan Shahid Madani University, 35km Tabriz-Maraqeh road, Tabriz, Iran

Key words: Callus induction, In vitro regeneration, Genotype dependency, Maize

\begin{abstract}
Tissue culture and genetic transformation in maize are very laborious. The existing regeneration methods, which mainly use immature embryos as starting material, are highly genotype-dependent. Leaf segments can be used as an alternative explant source to produce embryogenic calli. Although a reliable leafbased regeneration and transformation system has been recently reported for maize, however, the genotype-dependency of this method has not been described yet. To this end, we evaluated the production of embryogenic calli from young leaves of several maize genotypes. The results showed that, overall callus induction potential as well as embryogenic callus induction rate is significantly different among the tested genotypes, demonstrating the genotypedependency of this system. However, induced embryogenic calli from different genotypes remained their embryogenic capability during several callus multiplication rounds. In addition, embryogenic calli showed high potential for biolistic-based genetic transformation, as revealed by transient GUS expression.
\end{abstract}

\section{Introduction}

Maize (Zea mays L.) is one of the most important crop plants worldwide. Beside its agronomic importance, for nearly a century, maize has been a useful model organism for basic research (Liu et al. 2010). For several reasons such as increasing population, limited cultivation area, and extending biotic (pests and diseases) and abiotic (e. g., drought, salinity and cold) stresses, the demand for

*Author for correspondence: <m.ahmadabadi@azaruniv.ac.ir>, <ahmadabadiir@yahoo.com>.

DOI: https://doi.org/10.3329/ptcb.v28i2.39684 
enhanced quality and quantity of agricultural products has intensified (Naqvi et al. 2011). Progresses in plant genetic engineering methods have provided powerful tools for rapid development of genetically modified plants through molecular techniques (Thao and Tran 2016, Varshney et al. 2009).

In vitro regeneration techniques are of particular importance in plant genetic engineering. Although cereals, particularly maize, are classified as the main crops, tissue culture of these plants is facing numerous problems (Gould 1997). In maize, at present, immature embryos are the main explant sources to produce embryogenic calli with regeneration capacity (Ahmadabadi et al. 2007, Armstrong 1999, Bilang et al. 1999, Hansen and Wright 1999, Xiaoling et al. 2017). Although the immature embryos are effective as a source for callus induction in maize, but the process to produce and maintain embryogenic calli is very laborious and time-consuming, and due to its high genotype dependency, is limited to a small number of maize varieties. In addition to immature embryos, successful plant regeneration has also been reported from the anther (Ting et al. 1981), glume (Suprasanna et al. 1986), immature inflorescences (Pareddy and Petolino 1990), the shoot apical meristems (Zhang et al. 2002), mature seeds (Pathi et al. 2013) and leaf (Ahmadabadi et al. 2007) explants.

In most of the regeneration and transformation systems, leaf material is the preferred explant source, for several reasons: (i) it is rapidly produced from germinating seedlings that can readily be obtained at large amounts in a short time, (ii) seedling production will not be affected largely under greenhouse conditions, and (iii) allows multiple successive rounds of selection and regeneration, that the last is important for the development of organelle transformation technology for maize (Ahmadabadi et al. 2007). Recently, a leafbased regeneration and transformation system has been developed for maize by Ahmadabadi et al. (2007). Most of the maize tissue culture methods are highly dependent on the genotype (Armstrong 1999), however, the developed leafbased method has not been evaluated yet for its genotype dependency. In this research, in order to evaluate the applicability and genotype-dependency of the developed leaf-based tissue culture and regeneration system for maize, the production of embryogenic calli and subsequent plant regeneration from young leaves of several maize genotypes was evaluated.

\section{Materials and Methods}

Maize seeds (two lines of MO17 and B73, and two cultivars of 703 and 705, which are prevalent in Iran) were surface-sterilized in $70 \%$ ethanol for 5 minutes followed by 10 minutes incubation in $6 \%$ commercial bleach containing one drop of Tween 20. Seeds were then washed three times with sterile distilled water and 
cultured on $1 / 2 \mathrm{MS}$ medium (Murashige and Skoog 1962) complemented with 10 $\mathrm{g} /$ sucrose solidified with $2 \mathrm{~g} /$ Gelrite.

When the seedlings were $5-10 \mathrm{~cm}$ high, shoot fragments of $1-2 \mathrm{~cm}$ were excised from the bottom part of the shoots. After removing coleoptiles, individual leaf segments were sectioned longitudinally with a sharp scalpel into two to four thin strips. They were then sliced in thin cross-sections to generate small leaf pieces of approximately $1-2 \mathrm{~mm}^{2}$.

The small young leaf segments were transferred to callus induction medium containing N6 macro and micro elements complemented with KT vitamins (Horn et al. 1983), $2 \mathrm{mg} /$ glycine, $100 \mathrm{mg} /$ myo-inositol, $2880 \mathrm{mg} /$ proline, 650 $\mathrm{mg} / \mathrm{MgCl}_{2}, 100 \mathrm{mg} /$ casein hydrolysate, $2.2 \mathrm{mg} / 2,4-\mathrm{D}, 0.5 \mathrm{mM}$ spermidine and $20 \mathrm{~g} / \mathrm{sucrose}$ (Ahmadabadi et al. 2007). Due to the significant importance of the silver nitrate in increasing the quality and quality of callus induction in maize (Ahmadabadi et al. 2007), two concentrations of $500 \mathrm{mg} /$ and $1250 \mathrm{mg} /$ of the silver nitrate was evaluated. The $\mathrm{pH}$ of the medium was adjusted to 5.8. Silver nitrate and spermidine were added to the medium after autoclaving. The medium was solidified with $2.7 \mathrm{~g} /$ gelrite and maintained in the dark.

To evaluate the competence of embryogenic calli derived from different maize genotypes for biolistic transformation, the $\mathrm{pFF19G}$ vector (Timmermans et al. 1990) harboring the GUS gene under the control of CaMV-35S promoter and terminator was used. Embryogenic calli in small pieces (around $3 \mathrm{~mm}$ in diameter) were collected on the middle of a moist filter paper in a sterile glass Petri dish (roughly $3 \mathrm{~cm}$ ). The calli were then bombarded with plasmid-coated (pFF19G) gold particles $(0.6 \mu \mathrm{m}$ ) using a Bio-Rad Helium-driven PDS-1000/He particle gun. Bombarded calli were then placed on MS followed by incubation in growth chamber with a diurnal cycle of $16 \mathrm{hrs}$ light of $25 \mu \mathrm{E} / \mathrm{m}^{2} \mathrm{~s}$ at $25^{\circ} \mathrm{C}$ and 8 hrs dark period at $22^{\circ} \mathrm{C}$. After $24 \mathrm{hrs}$, histochemical GUS staining was carried out to evaluate GUS expression.

Bombarded calli were incubated in GUS staining solution [1 mM EDTA ( $\mathrm{pH}$ = 8), $5 \mathrm{mM}$ potassium ferricyanide, $5 \mathrm{mM}$ potassium ferrocyanide, $200 \mathrm{mM}$ potassium phosphate $(\mathrm{pH}=7.0), 1 \%$ Triton-X-100, $1 \mathrm{mg} / \mathrm{ml} \mathrm{X-Gluc]} \mathrm{for} \mathrm{overnight}$ at $37^{\circ} \mathrm{C}$. The blue color appearance, which demonstrates GUS expression, was then evaluated.

The adopted experimental design was completely randomized with three replicas. Callus induction and embryogenic callus formation was evaluated after 4 weeks and data analysis was performed by using SPSS statistical software version 19.0, and means were compared using the DMRT ( $\mathrm{p}<0.05)$. 


\section{Results and Discussion}

Embryogenic callus production from leaf segments of several maize genotypes including two inbred lines (MO17 and B73) and two Iranian commercial cultivars (703 and 705) was studied. The results showed that callus induction frequency is significantly different in genotypes (Table 1). This is the first report of the genotype-dependency of the leaf-based regeneration method proposed by Ahmadabadi et al. (2007), which suggests, like other previous approaches that have been developed for in vitro culture of maize, the efficiency of this method is rather genotype dependent. Among the genotypes, the best callus induction was obtained for cultivar 703 and line MO17. The callus induction capacity of line MO17 was maintained in two different levels of silver nitrate (Table 1), while, other genotypes showed significant differences in the two types of media (Table 1). Embryogenic callus formation (Fig. 1B, C) was observed only in these two genotypes.

Table 1. The frequency of callus induction and embryogenesis from leaf segments of four different maize genotypes after four weeks culture on the callus induction medium containing two different concentrations of silver nitrate (500 and 1250 $\mathrm{mg} / \mathrm{ll}$.

\begin{tabular}{lcccccc}
\hline \multirow{2}{*}{ Genotype } & \multicolumn{2}{c}{$500 \mathrm{mg} /$ silver nitrate } & & \multicolumn{2}{c}{$1250 \mathrm{mg} /$ silver nitrate } \\
\cline { 2 - 3 } \cline { 5 - 6 } & $\begin{array}{c}\text { Callus } \\
\text { induction }(\%)\end{array}$ & $\begin{array}{c}\text { Embryogenic } \\
\text { callus (\%) }\end{array}$ & & $\begin{array}{c}\text { Callus } \\
\text { induction }(\%)\end{array}$ & $\begin{array}{c}\text { Embryogenic } \\
\text { callus (\%) }\end{array}$ \\
\hline MO17 & $31.25^{\mathrm{ab}}$ & $7.4^{\mathrm{a}}$ & & $31.50^{\mathrm{a}}$ & $6.66^{\mathrm{a}}$ \\
B73 & $15.50^{\mathrm{c}}$ & $0^{\mathrm{b}}$ & & $10.20^{\mathrm{b}}$ & $0^{\mathrm{b}}$ \\
703 & $37.53^{\mathrm{a}}$ & $4.46^{\mathrm{a}}$ & & $23.16^{\mathrm{ab}}$ & $0^{\mathrm{b}}$ \\
705 & $21.83^{\mathrm{bc}}$ & $0^{\mathrm{b}}$ & & $26.16^{\mathrm{a}}$ & $0^{\mathrm{b}}$ \\
\hline
\end{tabular}

Values represent the mean of at least 10 replicas. Values indicated by different letters in the superscript, show significant difference at $p<0.05$, in comparison to the corresponding values of each experiment.

The lowest callus induction rate was recorded for line B73 in both media (Table 1). Also, this line and cultivar 705 did not produce any embryogenic callus in media. These results might indicate that there was direct relationship between callus induction and ability of plant in embryogenic callus production. The appearance of embryogenic calli was compact and yellow similar to the previously reported type I callus (Fig. 1C) (Armstrong 1999). The callus can be reproduced easily by cutting and maintained its embryogenic ability on culture medium containing $10 \mathrm{mg} /$ of silver nitrate for months without loss of regeneration ability (Fig. 1D). This result is important for gene transfer 
experiments. Another important point for gene transfer experiments is regeneration efficiency of the putative embryogenic calli. Embryogenic calli induced in this study, showed high ability to regeneration on ML1R3 medium (Ahmadabadi et al. 2007) (Fig. 1D). Regenerated plants easily produced roots and established in the soil. Positive effect of high levels of silver nitrate on callus induction has previously been reported (Ahmadabadi et al. 2007). However, this effect seems to be related to the genotype of the plant: while increasing of silver nitrate in the media showed a negative effect on callus induction from B73 line and 703 cultivar, the callus induction was improved in cultivar 705, and remained unchanged in MO17 line (Table 1).

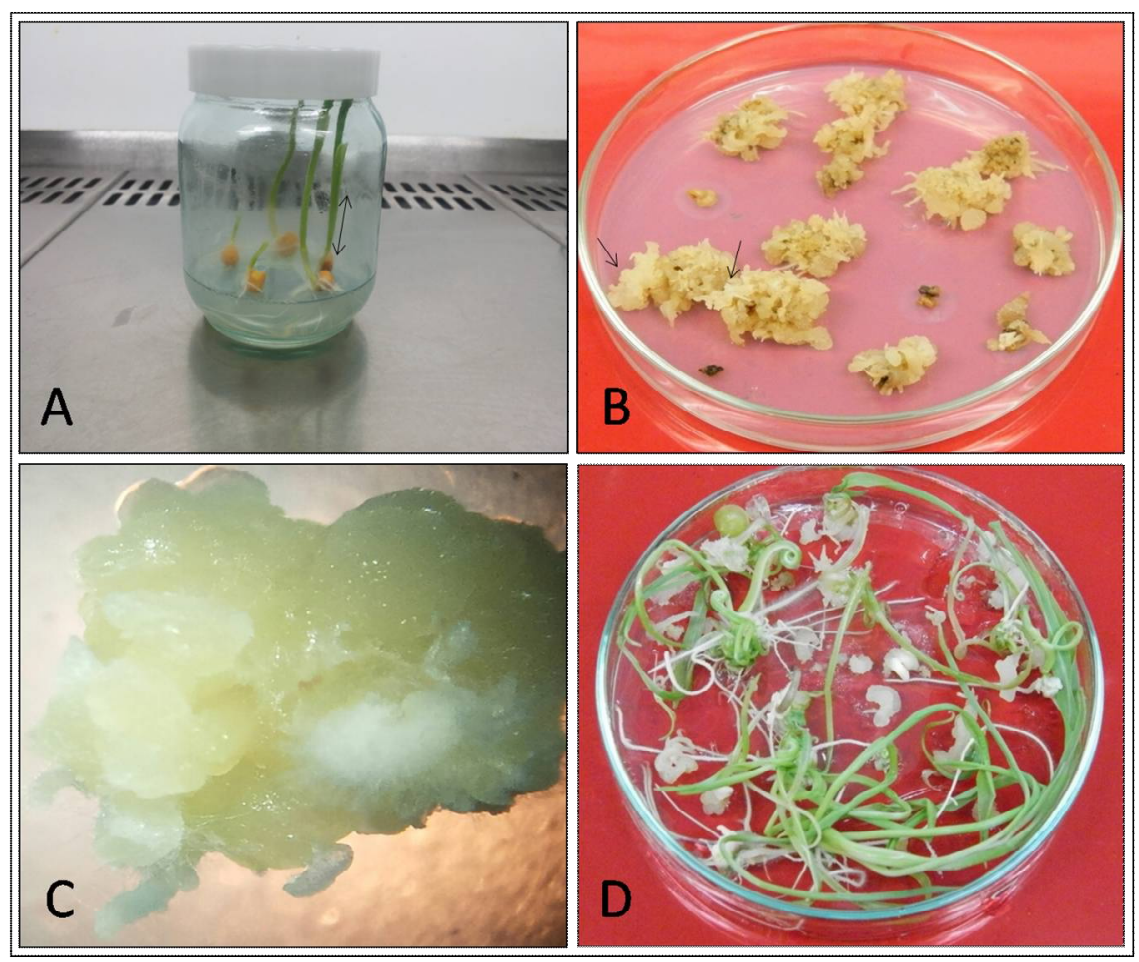

Fig. 1. Callus induction and plant regeneration in maize from young leaves. (A) Sterile maize seedlings. The area used for experiments is marked with arrow. (B) Callus induction after four weeks culture in the dark. Examples of embryogenic calli are shown with arrows. (C) A close-up of an embryogenic callus induced from maize leaf segments. (D) Efficient plant regeneration from leaf-derived embryogenic calli.

To evaluate the potential of induced embryogenic calli for genetic transformation, transient transformation and expression of the GUS reporter gene was carried out using biolistic gun. The results showed that the propagated embryogenic calli are highly competent for biolistic transformation method (Fig. 2). 


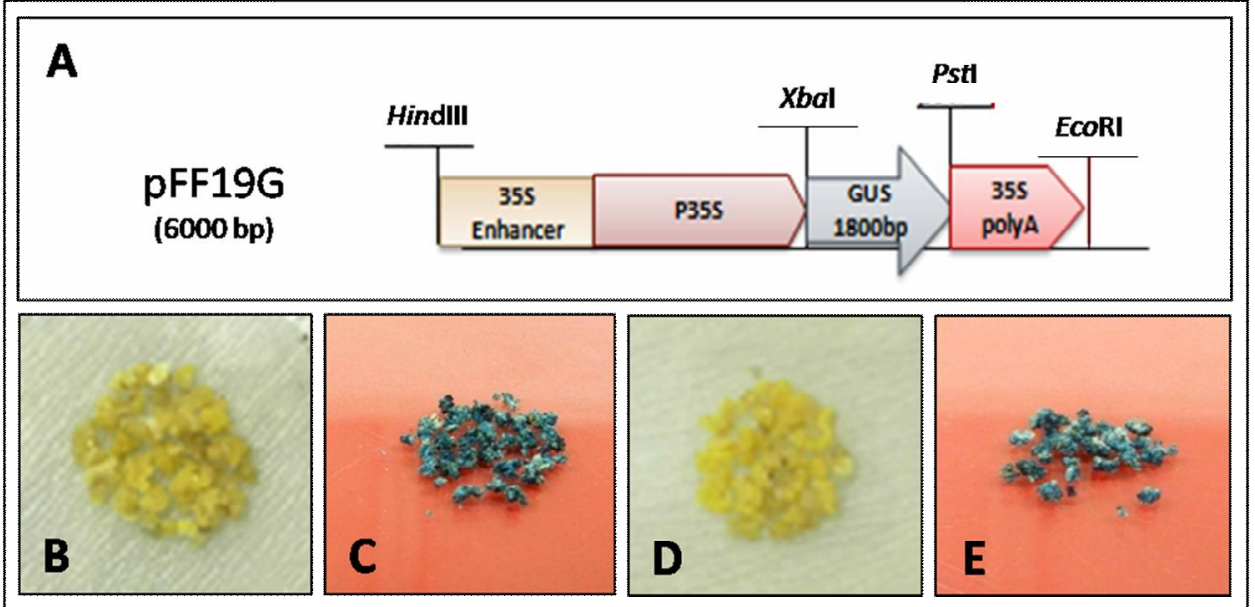

Fig. 2. Vector construction (A) and transient GUS expression in leaf-derived embryogenic calli via bilolistic transformation (B-E). B and D show embryogenic calli prepared for biolistic transformation, and C and E show same samples after biolistic transformation with pFF19G construct and GUS staining.

In 2007, Ahmadabadi et al. reported an efficient regeneration and gene transfer system for maize using young leaf segments of Pa91 $\times$ H99 genotype (Ahmadabadi et al. 2007). Yet, there are no reports on efficiency rate of this method in different genotypes, and therefore, the rate of genotype dependency of this method has not been identified so far. Here, this issue has been evaluated for the first time, and the results demonstrate that this system is highly genotype dependent. These results show that we still have much work to do for establishing tissue culture systems for maize that is less dependent on the genotype. Notwithstanding, this is the major problem in molecular breeding of almost all important cereal crops (Hiei et al. 2014, Ji et al. 2013). Generally, plant regeneration and tissue culture in monocots, especially cereals, is very difficult (Gould 1997, Ji et al. 2013). This problem also counts as the main limiting factor for developing gene transfer systems for organelles in monocots: although limited success of gene transfer into rice chloroplast has been reported, the system has failed so far to work for other cereals (Lee et al. 2006). Therefore, intensive studies need to be carried out to optimize more efficient in vitro tissue culture systems for important cereal crop plants such as maize. However, results of genomic, proteomic and metabolomic studies could help to have better understanding of mechanisms regulating callus induction, embryogenesis and regeneration by screening and optimization of multiple variables involved in the plant response to in vitro condition (Gago et al. 2011). 


\section{Acknowledgements}

The authors thank Azarbaijan Shahid Madani University for financial support.

\section{References}

Ahmadabadi M, Ruf S and Bock R (2007) A leaf-based regeneration and transformation system for maize (Zea mays L.). Transgenic Res. 16: 437-448.

Armstrong CL (1999) The first decade of maize transformation: A review and future perspectives. Maydica 44: 101-109.

Bilang R, Fütterer J and Sautter C (1999) Transformation of cereals. Genetic Engineering 21: 113-157.

Gago J, Perez-Tornero O, Landin M, Burgos L and Gallego PP (2011) Improving knowledge of plant tissue culture and media formulation by neurofuzzy logic: a practical case of data mining using apricot databases. J. Plant Physiol. 168: 1858-1865. http://dx.doi.org/10.1016/j.jplph.2011.04.008.

Gould J (1997) Transformation of the cereals using Agrobacterium. Methods Mol. Biol. 62: 491-501. http://dx.doi.org/10.1385/0-89603-480-1:491.

Hansen G and Wright MS (1999) Recent advances in the transformation of plants. Trends Plant Sci. 4: 226-231. http://dx.doi.org/10.1016/\$1360-1385(99)01412-0

Hiei Y, Ishida Y and Komari T (2014) Progress of cereal transformation technology mediated by Agrobacterium tumefaciens. Front. Plant Sci. 5: 628. http://dx.doi.org/ 10.3389 fpls.2014.00628.

Horn ME, Sherrard JH and Widholm JM (1983) Photoautotrophic growth of soybean cells in suspension culture: I. Establishment of photoautotrophic cultures. Plant Physiol. 72: 426-429.

Ji H, Pardo JM, Batelli G, Van Oosten MJ, Bressan RA and Li X (2013) The salt overly sensitive (SOS) pathway: Established and emerging roles. Mol. Plant 6: 275-286. http://dx.doi.org/10.1387/ijdb.130244kw.

Lee SM, Kang K, Chung H, Yoo SH, Xu XM, Lee SB, Cheong JJ, Daniell H and Kim M (2006) Plastid transformation in the monocotyledonous cereal crop, rice (Oryza sativa) and transmission of transgenes to their progeny. Mol. Cells 21: 401-410.

Liu H, He R, Zhang H, Huang Y, Tian M and Zhang J (2010) Analysis of synonymous codon usage in Zea mays. Mol. Biol. Rep. 37: 677-684. http://dx.doi.org/10.1007/s 11033-009-9521-7.

Naqvi S, Ramessar K, Farre G, Sabalza M, Miralpeix B, Twyman RM, Capell T, Zhu C and Christou P (2011) High-value products from transgenic maize. Biotechnol. Adv. 29: 40-53. http://dx.doi.org/10.1016/.biotechadv.2010.08.009.

Pareddy DR and Petolino JF (1990) Somatic embryogenesis and plant regeneration from immature inflorescences of several elite inbreds of maize. Plant Science 67: 211-219. http://dx.doi.org/10.1016/0168-9452(90)90245-J. 
Pathi KM, Tula S, Huda KM, Srivastava VK and Tuteja N (2013) An efficient and rapid regeneration via multiple shoot induction from mature seed derived embryogenic and organogenic callus of Indian maize (Zea mays L.). Plant Signal. Behav. 8 : Plant Signal. Behav. 8(10): e25891.

Suprasanna P, Rao KV and Reddy GM (1986) Plantlet regeneration from glume calli of maize (Zea mays L.). Theoretical and Applied Genetics 72: 120-122. http://dx.doi. org/10.1007/BF00261466.

Thao NP and Tran LS (2016) Enhancement of Plant Productivity in the Post-Genomics Era. Curr. Genomics 17 : 295-296.

Timmermans MC, Maliga P, Vieira J and Messing J (1990) The pFF plasmids: cassettes utilising CaMV sequences for expression of foreign genes in plants. J. Biotechnol. 14: 333-344.

Ting YC, Yu M and Zheng WZ (1981) Improved anther culture of maize. Plant Science 23: 139-145. http://dx.doi.org/10.1016/0304-4211(81)90003-1.

Varshney RK, Hoisington DA, Nayak SN and Graner A (2009) Molecular plant breeding: methodology and achievements. Methods Mol. Biol. 513: 283-304. http://dx.doi.org/ 10.1007 978-1-59745-427-8_15.

Xiaoling Z, Yun L, Fei G, Zhongrong G, Xiaoxiang Z, Yanli W, Yaou S and Guangtang P (2017) A genetic study of the regeneration capacity of embryonic callus from the maize immature embryo culture. Yi. Chuan. 39: 143-155.

Zhang S, Williams-Carrier R and Lemaux P (2002) Transformation of recalcitrant maize elite inbreds using in vitro shoot meristematic cultures induced from germinated seedlings. Plant Cell Rep. 21: 263-270. http://dx.doi.org/10.1007/s00299-002-0513-5. 